\title{
The calcium-dependent protein kinase 1 from Toxoplasma gondii as target for structure-based drug design
}

\author{
EMILY M. CARDEW ${ }^{1}$, CHRISTOPHE L. M. J. VERLINDE ${ }^{2}$ and EHMKE POHL EH, $^{1,4 *}$ \\ ${ }^{1}$ Department of Biosciences, Durham University, Lower Mountjoy Durham DH1 3LE, UK \\ ${ }^{2}$ Department of Biochemistry, University of Washington, Seattle, Washington, WA 98195, USA \\ ${ }^{3}$ Department of Chemistry, Durham University, South Road, Durham DH1 3LE, UK \\ ${ }^{4}$ Biophysical Sciences Institute, Durham University, Durham DH1 3LE, UK
}

(Received 31 May 2017; revised 11 August 2017; accepted 25 August 2017)

SUMMARY

The apicomplexan protozoan parasites include the causative agents of animal and human diseases ranging from malaria (Plasmodium spp.) to toxoplasmosis (Toxoplasma gondii). The complex life cycle of T. gondii is regulated by a unique family of calcium-dependent protein kinases (CDPKs) that have become the target of intensive efforts to develop new therapeutics. In this review, we will summarize structure-based strategies, recent successes and future directions in the pursuit of specific and selective inhibitors of $T$. gondii CDPK1.

Keywords: Calcium-dependent protein kinase, CDPK1, Toxoplasma gondii, drug design, protein structure.

\section{INTRODUCTION}

The phylum of Apicomplexa contains approximately 6000 unicellular, eukaryotic parasites including Plasmodium spp., the causative agent of Malaria, and Toxoplasma gondii, responsible for toxoplasmosis in many important farm animals and humans (Sato, 2011). Morphologically, all members of the apicomplexan family share a distinctive apical complex, together with species dependent apicallocalized organelles (McFadden and Yeh, 2017). These parasites employ complex life cycles including both sexual and asexual reproduction. Furthermore, in many cases their life cycles involve multiple hosts. T. gondii, first described in 1908 and often regarded as one of the most successful apicomplexan parasites, represents the key model organism of the phylum (Dubey, 2008; Weiss and Dubey, 2009; Szabo and Finney, 2017). Its primary hosts are members of the Felidae (cats) family while all other warm-blooded animals, including humans, are intermediate hosts. It is estimated that up to one third of the human population is infected with $T$. gondii and thus are potential carriers. Although the infection is usually asymptotic in healthy individuals it can cause severe congenital disease during pregnancy (Kaye, 2011), and lead to life-threatening infections in immuno-compromised patients including those suffering from HIV, receiving an organ transplant or undergoing cancer chemotherapy treatment (Flegr et al. 2014). Current toxoplasmosis treatment options are limited to a

\footnotetext{
* Corresponding author: Department of Biosciences, Durham University, Lower Mountjoy Durham DH1 3LE, UK, E-mail: ehmke.pohl@durham.ac.uk
}

handful of antimicrobials such as sulphonamides, folic acid derivatives and certain macrolide antibiotics. However, these drugs often show limited efficacy and are associated with significant side effects (Alday and Doggett, 2017). Furthermore, there are no treatments available to target tissue cysts, the persistent form in which the parasite evades the host immune system, and to eradicate persistent $T$. gondii infections (Opsteegh et al. 2015). Therefore, new drug targets and novel therapies are urgently needed. In addition to high-throughput screening approaches (Norcliffe et al. 2014), structure-based methods in close combination with medicinal chemistry and biophysical and biological validation have become powerful tools in the search of new drugs and treatments (Hunter, 2009; Verlinde et al. 2009; Groftehauge et al. 2015; Hol, 2015; Muller, 2017).

THE ROLE OF CALCIUM-DEPENDENT PROTEIN KINASES (CDPKS)

In $T$. gondii $\mathrm{Ca}^{2+}$-ions play key roles in cell signalling and in pathogen-host interactions including cell invasion, motility of the parasite within the host and differentiation during the parasites complex life cycle (Irvine, 1986; Nagamune et al. 2008; Lourido and Moreno, 2015). CDPKs are a family of serine/threonine kinases that are only found in plants and protists including ciliates and apicomplexan parasites. Importantly, these kinases provide the mechanistic link between calcium signalling and motility, differentiation and invasion (Tzen et al. 2007; Billker et al. 2009). These crucial roles of CDPKs have been proven through a range of knock-out studies in various species and underline the potential of CDPKs as targets for

Parasitology (2018), 145, 210-218. C Cambridge University Press 2017. This is an Open Access article, distributed under the terms of the Creative Commons Attribution licence (http://creativecommons.org/licenses/by/4.0/), which permits unrestricted re-use, distribution, and reproduction in any medium, provided the original work is properly cited. 
novel therapeutics (Long et al. 2016). CDPKs are members of the Calmodulin/Calcium kinase (CaM) family. They all share an N-terminal kinase domain (KD) linked via a junctional domain to a series of C-terminal Calcium-binding motifs. In T. gondii at least 12 different CDPKs have been putatively identified ranging in size from 507 (CDPK1) to more than 2000 amino acids (CDPK7, CDPK80) (Morlon-Guyot et al. 2014). Although there is probably overlap in functionalities, different sub-cellular locations and varying expression levels during the parasites' life cycle is likely to lead to different biological functions within the CDPK family (Hui et al. 2015). The shared sequence identities range from 51\% (CDPK1 and CDPK3) (Treeck et al. 2014) to lower than 10\% (Table 1). These variations in length and sequence support the notion that members of the CDPK family act upon a range of substrates and fulfil different functions in $T$. gondii biology. Recent knock-out studies using CRISPR-Cas9 indicate that CDPK4, CDPK5, CDPK6, CDPK8 and CDPK9, respectively, have no effect on virulence and on normal growth (Wang et al. 2016), however, knock-down studies have shown that CDPK7 is crucial for survival due to a critical role in parasite division (Morlon-Guyot et al. 2014). More detailed studies have been performed on the smaller family members. CDPK3 with 537 amino acids has been implicated in motility and host cell egress (McCoy et al. 2017). CDPK2 (711 amino acids) has been shown to act as key regulator of amylopectin metabolism (Uboldi et al. 2015). The loss of CDPK2 results in the build-up of amylum with fatal consequences for T. gondii in its chronic stage. Importantly, this family member contains an N-terminal carbohydrate-binding domain that may offer new opportunities for drug design (Uboldi et al. 2015). CDPK1, which is mainly located in the cytosol, has been shown to be required for the microneme secretion at the apical complex and parasite proliferation. The molecular mechanism, however, remains elusive (Lourido et al. 2010; Child et al. 2017). Here we will review strategies and recent results in the discovery, design and potency of inhibitors targeting the KD of CDPK1 from $T$. gondii ( $T g \mathrm{CDPK} 1)$.

\section{ACTIVATION OF $T G$ CDPK1 BY CALCIUM}

The mechanism of activation and inhibition was unravelled in 2010 when the crystal structures of both the auto-inhibited and the $\mathrm{Ca}^{2+}$-activated forms of $T g C D P K 1$ were published (Ojo et al. 2010; Wernimont et al. 2010). These structures revealed the expected $\mathrm{KD}$ in similar overall conformations, however, the $\mathrm{Ca}^{2+}$-binding domain (also designated CPDK activating domain or CAD) adopted two vastly different conformations and orientations (Fig. 1). In its inactive state the CAD

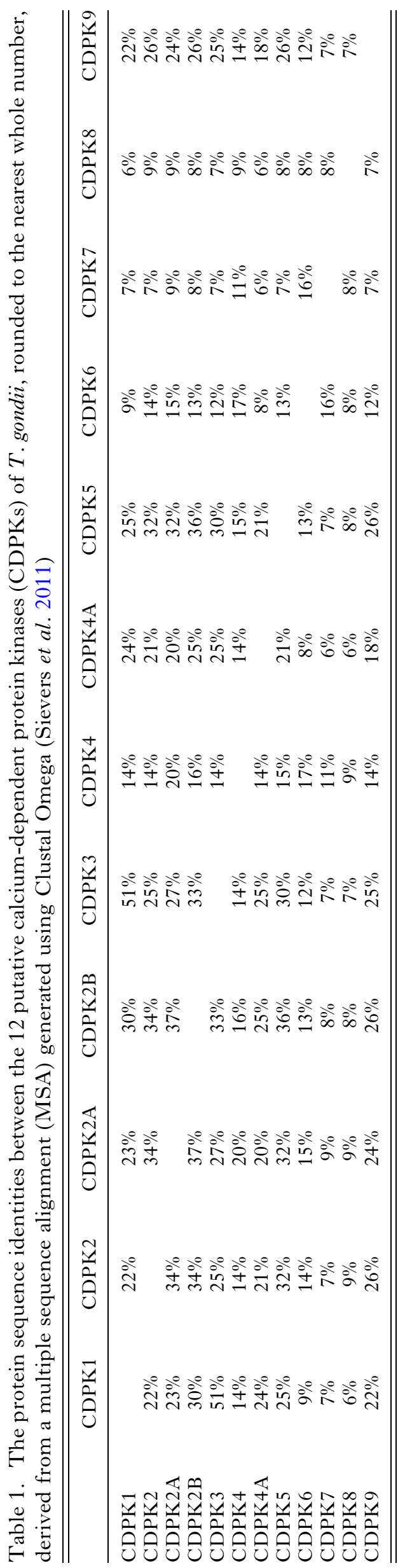


(a)

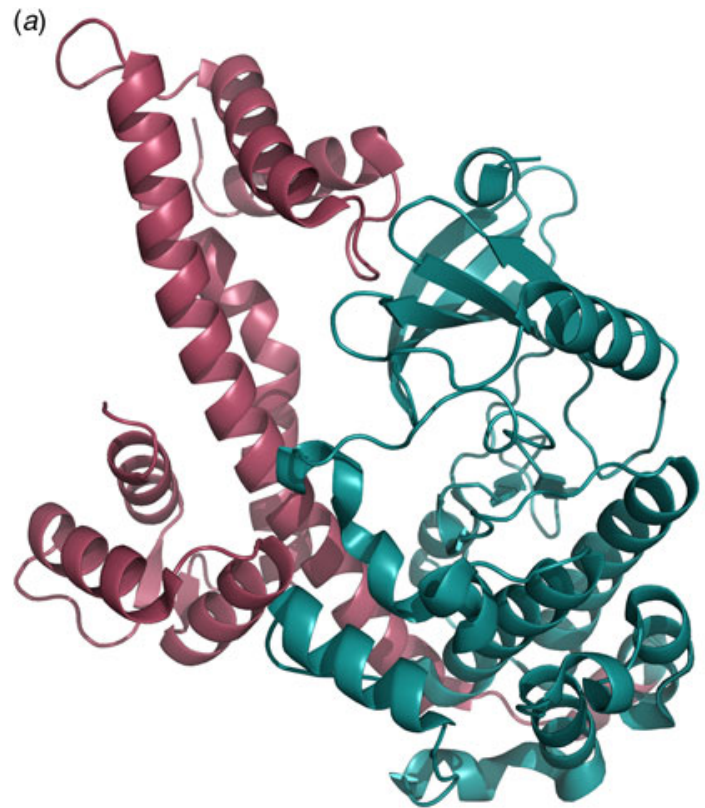

(b)

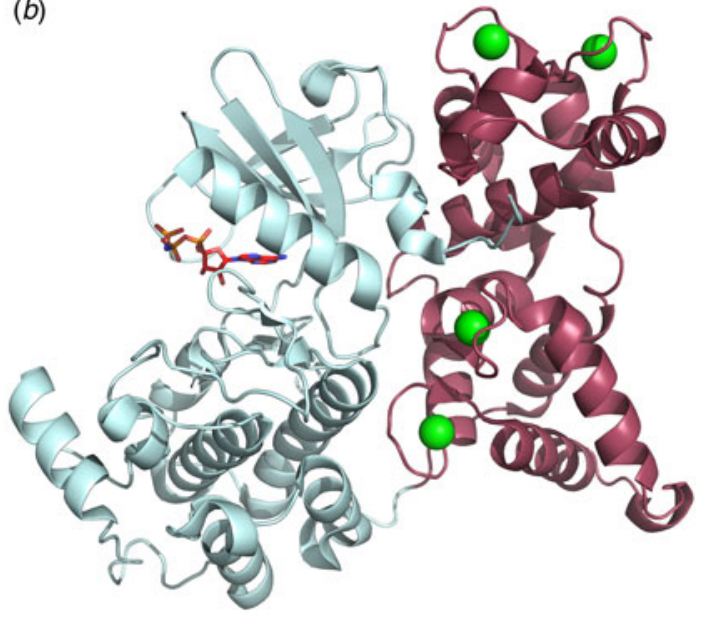

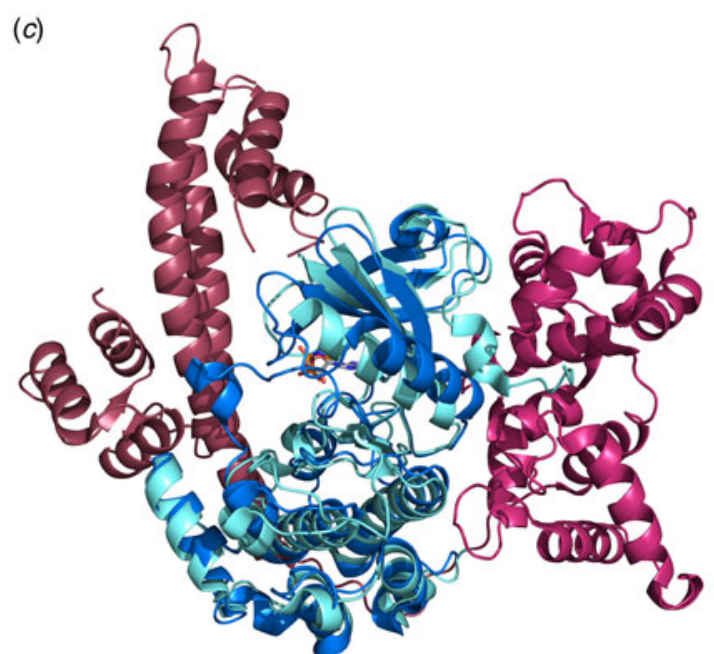

Fig. 1. Ribbon representation of the crystal structure of CDPK1 from $T$. gondii with the kinase domain depicted in cyan, the regulatory domain in raspberry red. (a) CDPK1 in its inactive auto-inhibited state (PDB code: 3KU2) (Wernimont et al. 2010). (b) CDPK1 in its calcium-bound, activated state with the $\mathrm{Ca}^{2+}$-ions shown as green spheres and the nonhydrolysable ligand ANP in stick representation (PDB code: 3HX4) (Wernimont et al. 2010). (c) Ribbon diagram of the least-squares superposition of the inactive and active forms of $T g$ CDPK1 with the kinase domains shown in cyan (active) and blue (inactive), the regulatory domain in shades of red, respectively. Only the kinase domain was used to calculate the transformation matrix, which was then applied to the entire protein chain. CDPKs, calcium-dependent protein kinases.

(shown in rasberry red) adopts an elongated form reminiscent of apo-calmodulin starting with a long helix followed by the first $\mathrm{Ca}^{2+}$-binding motifs (EF-hands), which is connected via another long helix to the second pair of C-terminal EF-hands (Fig. 1a). The first long helix has been suggested to be responsible for the auto-inhibitory effect by blocking the substrate binding site and providing a basic lysine residue to bind a cluster of conserved acidic residues. However, this may not be the only mechanism of deactivation as it has more recently been shown that removal of the regulatory domain alone does not lead to an active KD (Ingram et al. 2015). The CAD domain activated by $\mathrm{Ca}^{2+}$-binding appears to be required to maintain the $\mathrm{KD}$ in its active conformation. Calcium binding leads to a dramatic rearrangement and refolding of the protein chain (Fig. 1b) (Wernimont et al. 2010). The entire regulatory domain is shifted to the other side of the protein hence liberating the active site of the KD as shown in Fig. 1c. In addition, the regulatory calcium-binding domain is collapsed so that the two long helices are no longer arranged in an anti-parallel fashion but are partially unwound and interwoven to form a more globular overall shape. These structural changes are reminiscent to the calcium-bound structure of calmodulin (Kursula, 2014). 


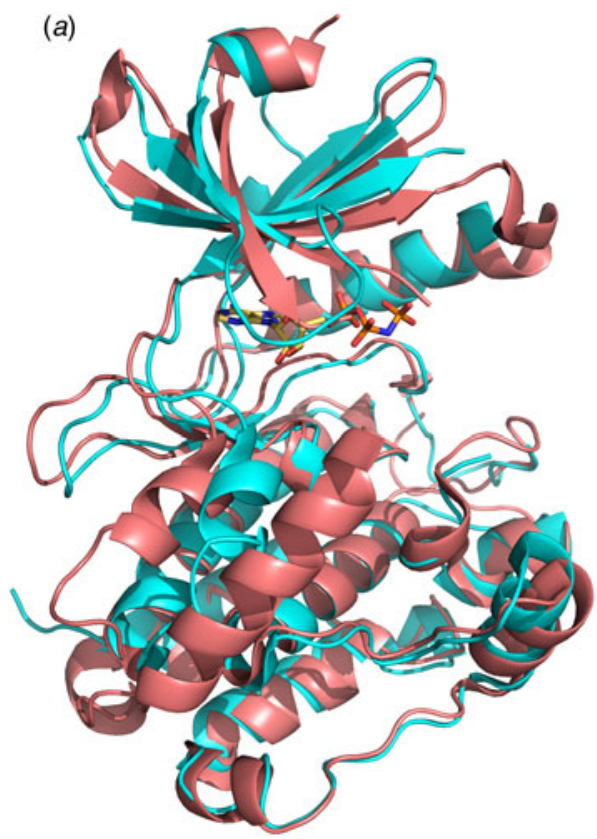

(b)

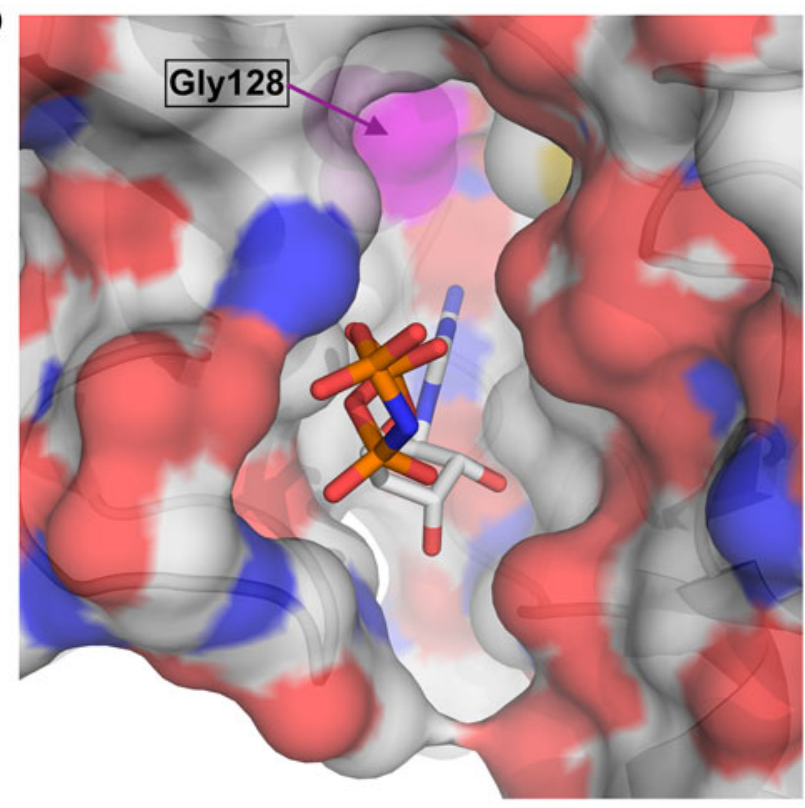

Fig. 2. (a) Least squares superposition of the kinase domain of $T g C D P K 1$ (depicted in cyan) in its active form with HsCaMKII bound to an inhibitor (PDB: 2VZ6) (shown in orange) (Rellos et al. 2010). The non-hydrolysable ATP analogue bound in $T g \mathrm{CDPK} 1$ is presented as ball-and-stick representation to highlight the substrate binding site. (b) Surface representation of $\mathrm{TgCDPK} 1$ viewing into the binding pocket with colour coding according to atom type (oxygen in red, nitrogen in blue, carbon in grey). The surface of Gly128 (gatekeeper residue) is shown in magenta at the top of the figure highlighting the additional space in the binding pocket. ATP, adenosine triphosphate; CDPKs, calcium-dependent protein kinases.

\section{COMPARISON WITH HUMAN KINASES}

Historically, characterising (protozoan) kinases as potential drug targets and developing selective inhibitors has been considered challenging due to the fact that the overall protein fold and the active sites of all kinases are structurally well conserved (Scapin, 2002). The structural similarities of the $\mathrm{KD}$ are obvious when comparing the crystal structures of the KD of TgCDPK1 with the Calcium/ Calmodulin (CaM) dependent-kinase II from $H$. sapiens (HsCaMKII) (Fig. 2a) (Rellos et al. 2010). These two proteins, which share a sequence identity of approximately $42 \%$ over 264 residues of the KD, display the same canonical kinase fold and superimpose with an overall root mean square deviation (rmsd) of approximately $1.5 \AA$. Note that the loop over the adenosine triphosphate (ATP) binding site adopts a very different conformation presumably due to an induced fit of binding of two very different ligands. TgCDPK1 is bound to the ATP analogue ANP (Fig. 2a) while $H s$ CaMKII is bound to a comparatively small inhibitor. More importantly there are significant differences in the ATP binding site, specifically a residue with no side chain (glycine) close to the adenine binding position. This residue, Gly128 is also termed the gatekeeper residue. Almost all mammalian kinases possess a large residue, a phenylalanine in $H s$ CaMKII for example, in this position. Hence, CDPK1 feature an enlarged ATP binding site with a hydrophobic pocket that can be exploited for structure-based drug design. This key structural difference in the binding pocket is shown in the surface representation where the ATP-analogue is shown as stick representation (Fig. 2b). The additional space at the end of the pocket below the surface of the gatekeeper residue Gly 128 in magenta is clearly visible.

\section{DEVELOPMENT OF SPECIFIC $T G$ CDPK 1} INHIBITORS

Soon after the structural differences between $T g$ CDPK1 and the mammalian homologues were identified, two groups started to develop selective TgCDPK1 inhibitors (Ojo et al. 2010; Wernimont et al. 2010). Initial compounds were based on known inhibitors previously developed for yeast kinases featuring amino acids with small side chains at the gatekeeper position. Importantly, these known kinase inhibitors, termed bumped kinase inhibitors (BKI) have been shown to be inactive against mammalian kinases (Hanke et al. 1996). Generally, BKIs are based on the planar pyrazolo[3,4- $d]$ pyrimidin-4amine substituted with a bulky hydrophobic group on the C3 position (Bishop et al. 1998). The first example of a $\mathrm{BKI}$ with a sub- $\mu$ molar $\mathrm{IC}_{50}$ is $1-(1-$ methylethyl)-3-(naphthalen-1 -ylmethyl)- $1 H$-pyrazolo[3,4-d] pyrimidin-4-amine. The co-crystal structure of $T g C D P K 1$ shows that the naphtalen1-ylmethyl- moiety fills the hydrophobic pocket 
(a)

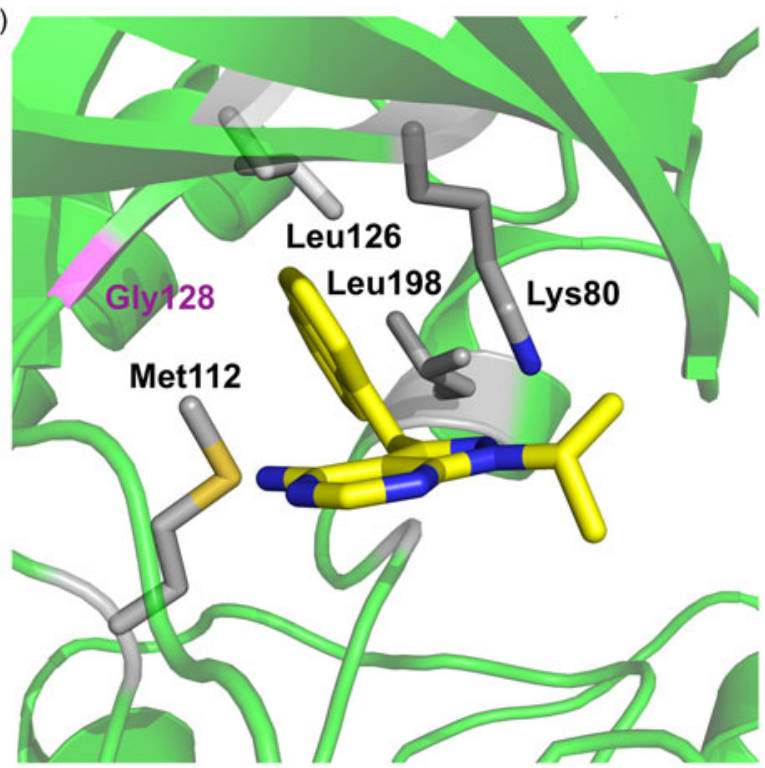

(c)

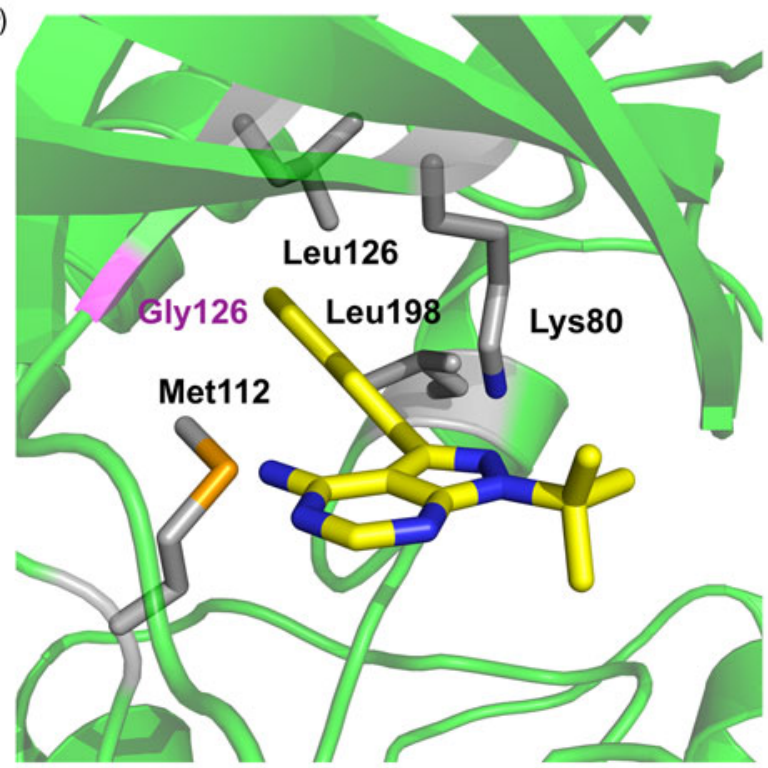

(b)

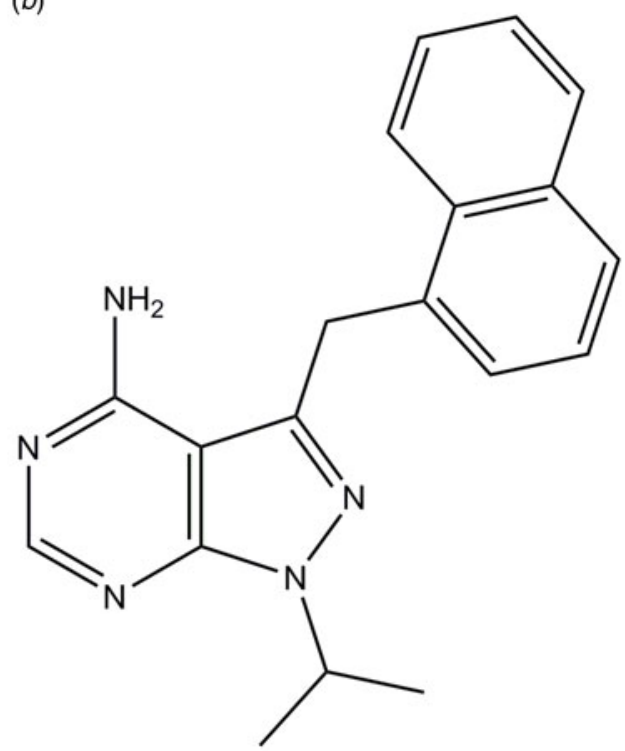

(d)

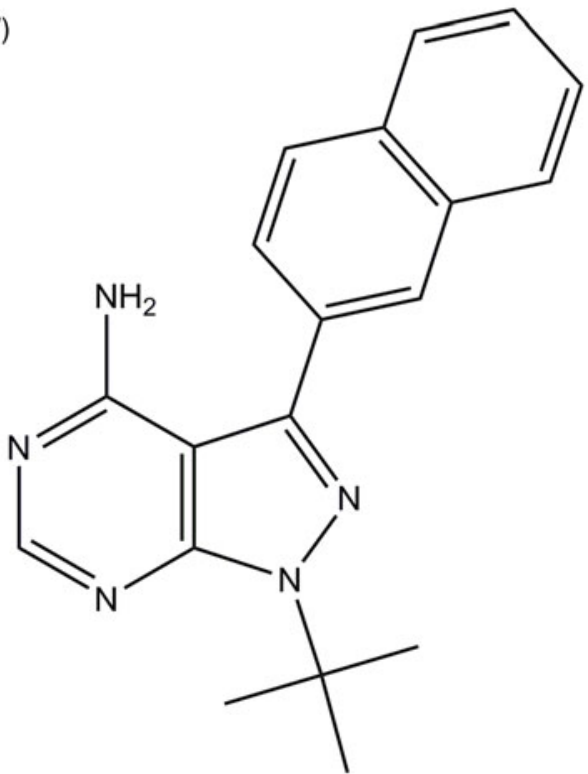

Fig. 3. Close-up of BKIs bound to TgCDPK1 in the ATP binding site. The gatekeeper residue Gly128 is depicted in magenta, key hydrophobic residue of the binding site are labelled and shown in grey (a) 1-(1-methylethyl)-3-(naphthalen1-ylmethyl)-1 $H$-pyrazolo[3,4- $d]$ pyrimidin-4-amine shown in ball-and-stick representation (PDB: $3 i 7 b)$, (b) chemical structure of the ligand, (c) 1-tert-butyl-3-naphthalen-2-yl-1H-pyrazolo[3,4- $d$ ]pyrimidin-4-amine (PDB:3i7c) (Ojo et al . 2010) and (d) chemical structure of the ligand. ATP, adenosine triphosphate; CDPKs, calcium-dependent protein kinases.

created by the small gatekeeper residue Gly128 and lined by methionine and leucine residues, and one lysine residue (Fig. 3a and b). The chemically closely related 1-tert-butyl-3-naphthalen-2-yl-1Hpyrazolo[3,4-d]pyrimidin-4-amine (Fig. 3c and d) adopts a similar conformation with the bulky aromatic substituent at the $\mathrm{C} 3$ position occupying the space next to the gatekeeper residue. Critically for the subsequent drug development was the fact that these and related BKIs reduced $T$. gondii proliferation significantly (Ojo et al. 2010; Sugi et al. 2010). These results sparked extensive medicinal chemistry efforts where a large number of compounds based on the BKI scaffold (4-amino- $1 H$-pyrazole[3,4$d]$ pyrimidine) were synthesized and tested. A number of compounds exhibited sub- or low-nanomolar $\mathrm{IC}_{50}$ values and high activity in parasite growth models $\left(\mathrm{EC}_{50}\right.$ in the low- and sub- $\mu$ molar range) while retaining specificity when compared with mammalian kinases (Lourido et al. 2013; Zhang et al. 2014; Moine et al. 2015). In addition to the pyrazolopyrimidine (PP) scaffolds, acylbenzimidazole and 5-aminopyrzazole-4-carboxamide-based compounds have been shown to have similar properties (Fig. 4) (Zhang et al. 2012; Zhang et al. 2014; Huang et al. 2015). While the initial BKIs showed excellent potency in vitro and in vivo they also exhibited significant hERG (human Ether-Related Gene) inhibition thus posing potential cardiotoxicity (Doggett et al. 2014). Further extensive medicinal chemistry efforts 
<smiles>[R2]n1nc(C(C)[Al])c2c(N)ncnc21</smiles><smiles></smiles>

Fig. 4. The three different scaffolds for TgCDPK1 inhibitors (a) pyrazolpyrimidines, (b) acylbenzimidazoles and (c) 5-aminopyrazole-4-carboxamide. CDPKs, calcium-dependent protein kinases.

finally led to the current lead $\operatorname{TgCDPK} 1$ inhibitor, (1-\{4-amino-3-[2-(cyclopropyloxy)quinolin-6-yl]$1 H$-pyrazolo[3,4- $d]$ pyrimidin-1-yl $\}$-2-methylpropan2-ol) that combines high activity and selectivity with favourable pharmacokinetic properties and low hERG activity (Vidadala et al. 2016). Note that the compound is bound to the protein via $\mathrm{H}$-bonds of the pyrimidin ring to the main chain, while the hydrophobic cyclopropyloxy-quinoline moiety forms a large number of hydrophobic interactions (Fig. 5). Taken together, the structure-based approaches of drug development applied to $T g C D P K 1$ has led to three different series of compounds with high inhibitory activity, good pharmacokinetic parameters and promising efficacy in murine models.

\section{CDPK1 INHIBITORS FOR RELATED PARASITES}

Based on the success of developing specific $T g$ CDPK1 inhibitors, recent work has branched out towards related apicomplexan parasites. For example, Neospora caninum, a cyst-forming parasite closely related to $T$. gondii represents the leading cause of abortion in cattle. This parasite expresses a CDPK1 with $96 \%$ sequence identity to $T g$ CDPK1 where all residues in the active side are conserved, bar one conservative variation from phenylalanine to tyrosine (Ojo et al. 2014). Consequently, the crystal structures of $T g C D P K 1$

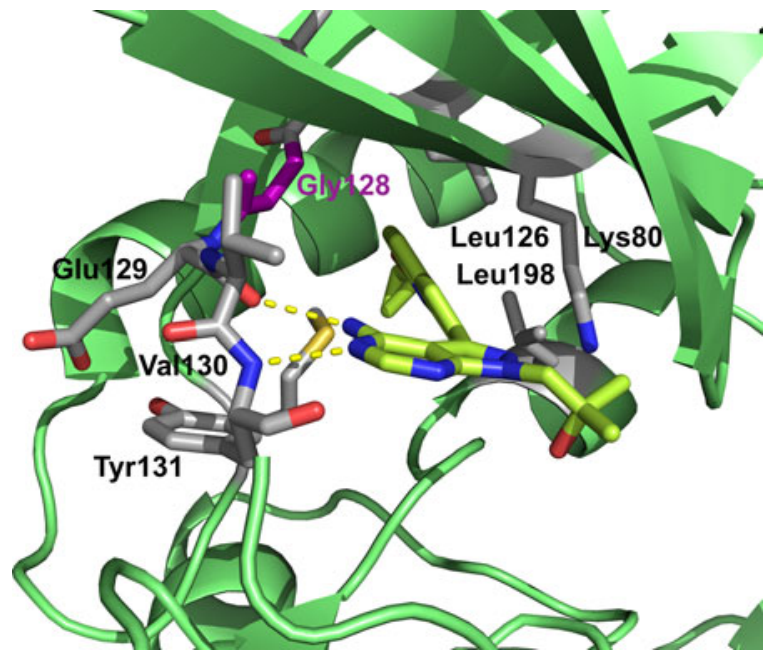

Fig. 5. Crystal structure of (1-\{4-amino-3-[2(cyclopropyloxy)quinolin-6-yl]-1H-pyrazolo[3,4- $d]$ pyrimidin-1-yl\}-2-methylpropan-2-ol) shown in stick representation bound to for $T g C D P K 1$ shown in cartoon representation with selected residues depicted in sticks (Vidadala et al. 2016). CDPKs, calcium-dependent protein kinases.

and $N c$ CDPK1 show very similar overall structures (root mean square deviations (rmsd) on C-alpha atoms $0 \cdot 5 \AA$ ) and the same binding mode of a BKI. Importantly, a number of BKIs display comparable in-vivo activities (Ojo et al. 2014; Winzer et al. 2015). Members of the Cryptosporidium genus are the causative agent of cryptosporidiosis in immunecompromised patients and malnourished children (Shoultz et al. 2016). CDPK1 from C. parvum Iowa II $(C p$ CDPK1) shares a sequence identity of approximately $41 \%$ with $T g C D P K 1$, however, the active site residues including the gatekeeper residue are highly conserved. The screening of BKI libraries resulted in highly active $C p$ CDPK1 inhibitors based on the 5-aminopyrazole-4-carboxamide scaffold with clear potential for drug development (Castellanos-Gonzalez et al. 2016). High-throughput screening for Plasmodium falciparum CDPK1 (PfCDPK1) inhibitors resulted in five chemical series, including the PP scaffold (Fig. 4a). $P f C D P K 1$ shares a sequence identity of approximately $47 \%$ with $T g C D P K 1$ and the gatekeeper residue threonine harbours a slightly larger side chain comparted to glycine. However, this side chain is still relatively small and mutational studies clearly indicated that these inhibitors bind at the same site (Ansell et al. 2014). More recent studies with PfCDPK1 inhibitors based on the chemically very similar Imidazopyridazine scaffold appear to show that these compounds also target cyclic GMP dependent kinases as well as Heat Shock Protein 90. These findings question the prospect of PfCDPK1 inhibitors for further drug development (Green et al. 2015). Taken together, these recent results show the potential of BKIs for future drug 
development in Toxoplasma and related parasites but they also illustrate the limitations of transferring detailed structural data to more distantly related proteins.

\section{FUTURE CHALLENGES}

Over the last 5 years there has been significant progress in the development of selective inhibitors of one of the key CDPKs from $T$. gondii achieved by taking advantage of a series of high-resolution crystal structures. While most of the previous research has focused on $T$. gondii, further efforts are currently underway to investigate inhibitors of CDPK1 from Cryptosporidium and Plasmodium spp. (Gaji et al. 2014; Green et al. 2015; Crowther et al. 2016). However, further research is required to unravel the biological roles of PfCDPKs and their potential as future drug targets (Kumar et al. 2017).

Although the most promising $T g$ CDPK1 inhibitors show high efficacy in murine models, future research is required to increase solubility and bioavailability in order to proceed to clinical trials. Furthermore, current lead compounds only target the ATP binding site of TgCDPK1. However, allosteric kinase inhibitors and modulators have shown enormous potential to target specific kinases and could be further exploited (Fang et al. 2013). Additional binding sites in less conserved regions such as the carbohydrate binding site recently discovered in $T g$ CDPK2 can serve as starting points for the development of new inhibitors (Uboldi et al. 2015). Clearly, more works needs to be done to understand the role of the other members of the Apicomplexan CDPK family. In this regard, the recent development of CRISPR/Cas 9 technology to modify the genes of members of the Apicomplexan family (Shen et al. 2014; Vinayak et al. 2015) will greatly facilitate the detailed analysis of the biological function of CDPK family members (Long et al. 2016; Wang et al. 2016).

\section{FINANCIAL SUPPORT}

This work was generously supported by the BBSRC grant $\mathrm{BB} / \mathrm{M} 024156 / 1$. In addition, we would like to thank the Biophysical Sciences Institute (BSI) for seed corn funding and the Institute for Advanced Studies (IAS) for a Senior Research Fellowship at Durham University to CLMV. EMC is grateful for a studentship by the Newcastle-Liverpool-Durham BBSRC Doctoral Training Partnership.

\section{REFERENCES}

Alday, P. H. and Doggett, J. S. (2017). Drugs in development for toxoplasmosis: advances, challenges, and current status. Drug Design Development and Therapy 11, 273-293.

Ansell, K. H., Jones, H. M., Whalley, D., Hearn, A., Taylor, D. L., Patin, E. C., Chapman, T.M., Osborne, S.A., Wallace, C., Birchall, K., Large, J., Bouloc, N., Smiljanic-Hurley, E., Clough, B., Moon, R. W., Green, J. L. and Holder, A. A. (2014).
Biochemical and antiparasitic properties of inhibitors of the Plasmodium falciparum calcium-dependent protein kinase PfCDPK1. Antimicrobial Agents and Chemotherapy 58, 6032-6043.

Billker, O., Lourido, S. and Sibley, L. D. (2009). Calcium-dependent signaling and kinases in apicomplexan parasites. Cell Host \& Microbe 5, 612-622.

Bishop, A. C., Shah, K., Liu, Y., Witucki, L., Kung, C. and Shokat, K. M. (1998). Design of allele-specific inhibitors to probe protein kinase signaling. Current Biology 8, 257-266.

Castellanos-Gonzalez, A., Sparks, H., Nava, S., Huang, W. Zhang, Z., Rivas, K., Hulverson, M. A., Barrett, L. K., Ojo, K. K., Fan, E., Van Voorhis, W. C. and White, A.C., Jr. (2016). A novel calcium-dependent kinase inhibitor, bumped kinase inhibitor 1517 , cures cryptosporidiosis in immunosuppressed mice. Fournal of Infectious Diseases 214, 1850-1855.

Child, M. A., Garland, M., Foe, I., Madzelan, P., Treeck, M., van der Linden, W. A., Oresic Bender, K., Weerapana, E., Wilson, M. A., Boothroyd, J. C., Reese, M. L. and Bogyo, M. (2017). Toxoplasma DJ-1 regulates organelle secretion by a direct interaction with calciumdependent protein kinase 1. MBio 8, e02189-16.

Crowther, G. J., Hillesland, H. K., Keyloun, K. R., Reid, M. C., Lafuente-Monasterio, M. J., Ghidelli-Disse, S., Leonard, S. E., He, P., Jones, J. C., Krahn, M. M., Mo, J.S., Dasari, K. S., Fox, A. M., Boesche, M., El Bakkouri, M., Rivas, K. L., Leroy, D., Hui, R., Drewes, G., Maly, D. J., Van Voorhis, W.C. and Ojo, K. K. (2016). Biochemical screening of five protein kinases from Plasmodium falciparum against 14000 cell-active compounds. PLoS ONE 11, e0149996.

Doggett, J. S., Ojo, K. K., Fan, E., Maly, D. J. and Van Voorhis, W. C. (2014). Bumped kinase inhibitor 1294 treats established Toxoplasma gondii infection. Antimicrobial Agents and Chemotherapy 58, 3547-3549.

Dubey, J. P. (2008). The history of Toxoplasma gondii - the first 100 years. Fournal of Eukaryotic Microbiology 55, 467-475.

Fang, Z., Grutter, C. and Rauh, D. (2013). Strategies for the selective regulation of kinases with allosteric modulators: exploiting exclusive structural features. ACS Chemical Biology 8, 58-70.

Flegr, J., Prandota, J., Sovickova, M. and Israili, Z. H. (2014). Toxoplasmosis - a global threat. Correlation of latent toxoplasmosis with specific disease burden in a set of 88 countries. PLoS ONE 9, e90203.

Gaji, R.Y., Checkley, L., Reese, M.L., Ferdig, M. T. and Arrizabalaga, G. (2014). Expression of the essential kinase PfCDPK1 from Plasmodium falciparum in Toxoplasma gondii facilitates the discovery of novel antimalarial drugs. Antimicrobial Agents and Chemotherapy 58, 2598-2607.

Green, J. L., Moon, R. W., Whalley, D., Bowyer, P. W., Wallace, C., Rochani, A., Nageshan, R. K., Howell, S. A., Grainger, M., Jones, H.M., Ansell, K.H., Chapman, T.M., Taylor, D. L., Osborne, S. A., Baker, D. A., Tatu, U. and Holder, A. A. (2015). Imidazopyridazine inhibitors of Plasmodium falciparum calciumdependent protein kinase 1 also target cyclic GMP-dependent protein kinase and heat shock protein 90 to kill the parasite at different stages of intracellular development. Antimicrobial Agents and Chemotherapy 60, 1464-1475.

Groftehauge, M. K., Hajizadeh, N. R., Swann, M. J. and Pohl, E. (2015). Protein-ligand interactions investigated by thermal shift assays (TSA) and dual polarization interferometry (DPI). Acta Crystallographica Section D, Biological Crystallography 71, 36-44.

Hanke, J.H., Gardner, J.P., Dow, R. L., Changelian, P.S., Brissette, W. H., Weringer, E. J., Pollok, B. A. and Connelly, P. A. (1996). Discovery of a novel, potent, and Src family-selective tyrosine kinase inhibitor. Study of Lck- and FynT-dependent T cell activation. Fournal of Biological Chemistry 271, 695-701.

Hol, W. G. (2015). Three-dimensional structures in the design of therapeutics targeting parasitic protozoa: reflections on the past, present and future. Acta Crystallographica F Structural Biology Communications 71, 485-499.

Huang, W., Ojo, K. K., Zhang, Z., Rivas, K., Vidadala, R.S., Scheele, S., DeRocher, A.E., Choi, R., Hulverson, M. A., Barrett, L. K., Bruzual, I., Siddaramaiah, L. K., Kerchner, K. M., Kurnick, M. D., Freiberg, G. M., Kempf, D., Hol, W. G., Merritt, E. A., Neckermann, G., de Hostos, E. L., Isoherranen, N., Maly, D. J., Parsons, M., Doggett, J.S., Van Voorhis, W. C. and Fan, E. (2015). SAR studies of 5-aminopyrazole-4-carboxamide analogues as potent and selective inhibitors of Toxoplasma gondii CDPK1. ACS Medicinal Chemistry Letters 6, 1184-1189.

Hui, R., El Bakkouri, M. and Sibley, L. D. (2015). Designing selective inhibitors for calcium-dependent protein kinases in apicomplexans. Trends in Pharmacological Sciences 36, 452-460. 
Hunter, W. N. (2009). Structure-based ligand design and the promise held for antiprotozoan drug discovery. Fournal of Biological Chemistry 284, 11749-11753.

Ingram, J. R., Knockenhauer, K. E., Markus, B. M., Mandelbaum, J., Ramek, A., Shan, Y., Shaw, D. E., Schwartz, T. U., Ploegh, H. L. and Lourido, S. (2015). Allosteric activation of apicomplexan calcium-dependent protein kinases. Proceedings of the National Academy of Sciences of the United States of America 112, E4975-E4984.

Irvine, R. F. (1986). Calcium transients: mobilization of intracellular $\mathrm{Ca}^{2+}$ British Medical Bulletin 42, 369-374.

Kaye, A. (2011). Toxoplasmosis: diagnosis, treatment, and prevention in congenitally exposed infants. Fournal of Pediatric Health Care 25, 355-364. Kumar, S., Kumar, M., Ekka, R., Dvorin, J. D., Paul, A. S., Madugundu, A. K., Gilberger, T., Gowda, H., Duraisingh, M. T., Keshava Prasad, T.S. and Sharma, P. (2017). PfCDPK1 mediated signaling in erythrocytic stages of Plasmodium falciparum. Nature Communications 8, 63.

Kursula, P. (2014). The many structural faces of calmodulin: a multitasking molecular jackknife. Amino Acids 46, 2295-2304.

Long, S., Wang, Q. and Sibley, L. D. (2016). Analysis of noncanonical calcium-dependent protein kinases in Toxoplasma gondii by targeted gene deletion using CRISPR/Cas9. Infection and Immunity 84, 1262-1273.

Lourido, S. and Moreno, S. N. (2015). The calcium signaling toolkit of the Apicomplexan parasites Toxoplasma gondii and Plasmodium spp. Cell Calcium 57, 186-193.

Lourido, S., Shuman, J., Zhang, C., Shokat, K. M., Hui, R. and Sibley, L. D. (2010). Calcium-dependent protein kinase 1 is an essential regulator of exocytosis in Toxoplasma. Nature 465, 359-362.

Lourido, S., Jeschke, G. R., Turk, B.E. and Sibley, D. (2013). Exploiting the unique ATP-binding pocket of toxoplasma calciumdependent protein kinase 1 to identify its substrates. ACS Chemical Biology 8, 1155-1162.

McCoy, J. M., Stewart, R. J., Uboldi, A. D., Li, D., Schroder, J., Scott, N. E., Papenfuss, A. T., Lehane, A.M., Foster, L. J. and Tonkin, C. J. (2017). A forward genetic screen identifies a negative regulator of rapid $\mathrm{Ca}^{2+}$-dependent cell egress (MS1) in the intracellular parasite Toxoplasma gondii. Fournal of Biological Chemistry 292, 7662-7674.

McFadden, G. I. and Yeh, E. (2017). The apicoplast: now you see it, now you don't. International Fournal for Parasitology 47, 137-144.

Moine, E., Dimier-Poisson, I., Enguehard-Gueiffier, C., Logé, C., Pénichon, M., Moiré, N., Delehouzé, C., Foll-Josselin, B., Ruchaud, S., Bach, S., Gueiffier, A., Debierre-Grockiego, F. and Denevault-Sabourin, C. (2015). Development of new highly potent imidazo[1,2-b]pyridazines targeting Toxoplasma gondii calcium-dependent protein kinase 1. European Fournal of Medicinal Chemistry 105, 80-105

Morlon-Guyot, J., Berry, L., Chen, C. T., Gubbels, M. J., Lebrun, M. and Daher, W. (2014). The Toxoplasma gondii calcium-dependent protein kinase 7 is involved in early steps of parasite division and is crucial for parasite survival. Cellular Microbiology 16, 95-114.

Muller, I. (2017). Guidelines for the successful generation of proteinligand complex crystals. Acta Crystallographica D Structural Biology 73, 79-92.

Nagamune, K., Moreno, S. N., Chini, E. N. and Sibley, L. D. (2008). Calcium regulation and signaling in apicomplexan parasites. Subcellular Biochemistry 47, 70-81.

Norcliffe, J. L., Alvarez-Ruiz, E., Martin-Plaza, J. J., Steel, P. G. and Denny, P. W. (2014). The utility of yeast as a tool for cell-based, targetdirected high-throughput screening. Parasitology 141, 8-16.

Ojo, K. K., Larson, E. T., Keyloun, K. R., Castaneda, L. J., Derocher, A. E., Inampudi, K. K., Kim, J. E., Arakaki, T. L., Murphy, R. C., Zhang, L., Napuli, A. J., Maly, D. J., Verlinde, C. L., Buckner, F.S., Parsons, M., Hol, W. G., Merritt, E. A. and Van Voorhis, W.C. (2010). Toxoplasma gondii calcium-dependent protein kinase 1 is a target for selective kinase inhibitors. Nature Structural $\mathcal{\sigma}^{\circ}$ Molecular Biology 17, 602-607.

Ojo, K. K., Reid, M. C., Kallur Siddaramaiah, L., Muller, J., Winzer, P., Zhang, Z., Keyloun, K. R., Vidadala, R.S., Merritt, E. A., Hol, W. G., Maly, D. J., Fan, E., Van Voorhis, W.C. and Hemphill, A. (2014). Neospora caninum calcium-dependent protein kinase 1 is an effective drug target for neosporosis therapy. PLoS ONE 9, e92929.

Opsteegh, M., Kortbeek, T.M., Havelaar, A.H. and van der Giessen, J. W. (2015). Intervention strategies to reduce human Toxoplasma gondii disease burden. Clinical Infectious Diseases 60, 101-107. Rellos, P., Pike, A.C., Niesen, F.H., Salah, E., Lee, W. H., von Delft, F. and Knapp, S. (2010). Structure of the CaMKIIdelta/calmodulin complex reveals the molecular mechanism of CaMKII kinase activation. PLoS Biology 8, e1000426.
Sato, S. (2011). The apicomplexan plastid and its evolution. Cellular and Molecular Life Sciences 68, 1285-1296.

Scapin, G. (2002). Structural biology in drug design: selective protein kinase inhibitors. Drug Discovery Today 7, 601-611.

Shen, B., Brown, K. M., Lee, T. D. and Sibley, L. D. (2014). Efficient gene disruption in diverse strains of Toxoplasma gondii using CRISPR/ CAS9. MBio 5, e01114-e01114.

Shoultz, D. A., de Hostos, E. L. and Choy, R. K. (2016). Addressing cryptosporidium infection among young children in low-income settings: the crucial role of new and existing drugs for reducing morbidity and mortality. PLoS Neglected Tropical Diseases 10, e0004242.

Sievers, F., Wilm, A., Dineen, D., Gibson, T. J., Karplus, K., Li, W., Lopez, R., McWilliam, H., Remmert, M., Söding, J., Thompson, J. D. and Higgins, D. G. (2011). Fast, scalable generation of high-quality protein multiple sequence alignments using Clustal Omega. Molecular Systems Biology 7, 539.

Sugi, T., Kato, K., Kobayashi, K., Watanabe, S., Kurokawa, H., Gong, H., Pandey, K., Takemae, H. and Akashi, H. (2010). Use of the kinase inhibitor analog 1NM-PP1 reveals a role for Toxoplasma gondii CDPK1 in the invasion step. Eukaryotic Cell 9, 667-670.

Szabo, E. K. and Finney, C. A. (2017). Toxoplasma gondii: one organism, multiple models. Trends in Parasitology 33, 113-127.

Treeck, M., Sanders, J. L., Gaji, R. Y., LaFavers, K. A., Child, M. A., Arrizabalaga, G., Elias, J. E. and Boothroyd, J. C. (2014). The calciumdependent protein kinase 3 of toxoplasma influences basal calcium levels and functions beyond egress as revealed by quantitative phosphoproteome analysis. PLoS Pathogens 10, e1004197.

Tzen, M., Benarous, R., Dupouy-Camet, J. and Roisin, M. P. (2007). A novel Toxoplasma gondii calcium-dependent protein kinase. Parasite 14, 141-147.

Uboldi, A. D., McCoy, J. M., Blume, M., Gerlic, M., Ferguson, D. J., Dagley, L.F., Beahan, C. T., Stapleton, D. I., Gooley, P. R., Bacic, A., Masters, S. L., Webb, A.I., McConville, M. J. and Tonkin, C. J. (2015). Regulation of starch stores by a Ca(2+)-dependent protein kinase Is essential for viable cyst development in Toxoplasma gondii. Cell Host \& Microbe 18, 670-681.

Verlinde, C. L., Fan, E., Shibata, S., Zhang, Z., Sun, Z., Deng, W., Ross, J., Kim, J., Xiao, L., Arakaki, T. L., Bosch, J., Caruthers, J. M., Larson, E. T., Letrong, I., Napuli, A., Kelly, A., Mueller, N., Zucker, F., Van Voorhis, W. C., Buckner, F. S., Merritt, E. A. and Hol, W. G. (2009). Fragment-based cocktail crystallography by the medical structural genomics of pathogenic protozoa consortium. Current Topics in Medicinal Chemistry 9, 1678-1687.

Vidadala, R.S., Rivas, K.L., Ojo, K. K., Hulverson, M. A., Zambriski, J. A., Bruzual, I., Schultz, T. L., Huang, W., Zhang, Z., Scheele, S., DeRocher, A.E., Choi, R., Barrett, L. K., Siddaramaiah, L. K., Hol, W. G., Fan, E., Merritt, E. A., Parsons, M., Freiberg, G., Marsh, K., Kempf, D. J., Carruthers, V. B., Isoherranen, N., Doggett, J.S., Van Voorhis, W. C. and Maly, D. J. (2016). Development of an orally available and central nervous system (CNS) penetrant Toxoplasma gondii calcium-dependent protein kinase 1 ( $T g C D P K 1)$ inhibitor with minimal human ether-a-gogo-related gene (hERG) activity for the treatment of toxoplasmosis. Fournal of Medicinal Chemistry 59, 6531-6546.

Vinayak, S., Pawlowic, M.C., Sateriale, A., Brooks, C.F., Studstill, C. J., Bar-Peled, Y., Cipriano, M. J. and Striepen, B. (2015). Genetic modification of the diarrhoeal pathogen Cryptosporidium parvum. Nature 523, 477-480.

Wang, J. L., Huang, S. Y., Li, T. T., Chen, K., Ning, H. R. and Zhu, X. Q. (2016). Evaluation of the basic functions of six calcium-dependent protein kinases in Toxoplasma gondii using CRISPR-Cas9 system. Parasitology Research 115, 697-702.

Weiss, L. M. and Dubey, J. P. (2009). Toxoplasmosis: a history of clinical observations. International fournal for Parasitology 39, 895-901.

Wernimont, A. K., Artz, J. D., Finerty, P., Jr., Lin, Y. H., Amani, M., Allali-Hassani, A., Senisterra, G., Vedadi, M., Tempel, W., Mackenzie, F., Chau, I., Lourido, S., Sibley, L. D. and Hui, R. (2010). Structures of apicomplexan calcium-dependent protein kinases reveal mechanism of activation by calcium. Nature Structural $\xi^{\circ}$ Molecular Biology 17, 596-601.

Winzer, P., Müller, J., Aguado-Martinez, A., Rahman, M., Balmer, V., Manser, V., Ortega-Mora, L. M., Ojo, K. K., Fan, E., Maly, D. J., Van Voorhis, W. C. and Hemphill, A. (2015). In vitro and in vivo effects of the bumped kinase inhibitor 1294 in the related cyst-forming apicomplexans Toxoplasma gondii and Neospora caninum. Antimicrobial Agents and Chemotherapy 59,6361-6374.

Zhang, Z., Ojo, K. K., Johnson, S. M., Larson, E. T., He, P., Geiger, J. A., Castellanos-Gonzalez, A., White, A.C., Jr., Parsons, M., 
Merritt, E. A., Maly, D. J., Verlinde, C. L., Van Voorhis, W. C. and Fan, E. (2012). Benzoylbenzimidazole-based selective inhibitors targeting Cryptosporidium parvum and Toxoplasma gondii calcium-dependent protein kinase-1. Bioorganic \& Medicinal Chemistry Letters 22, 5264-5267.

Zhang, Z., Ojo, K. K., Vidadala, R., Huang, W., Geiger, J. A. Scheele, S., Choi, R., Reid, M.C., Keyloun, K. R., Rivas, K.,
Siddaramaiah, L. K., Comess, K. M., Robinson, K. P., Merta, P. J., Kifle, L., Hol, W. G., Parsons, M., Merritt, E. A., Maly, D. J., Verlinde, C. L., Van Voorhis, W. C. and Fan, E. (2014). Potent and selective inhibitors of CDPK1 from T. gondii and C. parvum based on a 5-aminopyrazole-4-carboxamide scaffold. ACS Medical Chemistry Letters 5, 40-44. 